\title{
Wood acetylation: a potential route towards climate change mitigation
}

\author{
P. van der Lugt \& J.G. Vogtländer \\ Design for Sustainability Program, \\ Faculty of Industrial Design Engineering, \\ Delft University of Technology, The Netherlands
}

\begin{abstract}
Climate change is increasingly acknowledged as a threat to human society. In the global warming debate, the role of forests and wood products increasingly gains attention considering their important impact - both negative and positive - through deforestation, forest conservation, afforestation and increasing application of wood in durable (construction) products acting as carbon sink. A promising route enabling legally and sustainably sourced non-durable temperate wood species to be used in high performance applications is through large scale non-toxic wood modification, of which acetylation is one of the leading methods. To gain a better understanding of the difference in greenhouse gas emissions of acetylated scots pine, tropical hardwood (azobe) and non-renewable materials (steel, concrete), this study first presents the emissions in terms of $\mathrm{kg} \mathrm{CO}_{2}$ equivalent based on a cradleto-gate scenario. Since the cradle-to-gate assessment excludes relevant use-phase and end-of-life related aspects, the second part of this study takes the production results as input for an assessment of the full life cycle (cradle-to-grave) with the bearing structure of a typical pedestrian bridge as fair unit of comparison for all material alternatives. The results show that acetylated wood has a considerably lower carbon footprint than steel, concrete and unsustainably sourced azobe, and slightly lower than sustainably sourced azobe. Because of the limited emissions during production and carbon credits related to carbon sequestration as a result of land-use change and bio-energy production during the end-of-life phase, all sustainably sourced wood alternatives, including acetylated wood, show $\mathrm{CO}_{2}$ negative LCA results over the full life cycle.

Keywords: acetylated wood, greenhouse gas emissions, climate change mitigation, carbon footprint, green building.
\end{abstract}




\section{Introduction}

Climate change is increasingly being acknowledged as a threat to our environment and human society. There are various strategies for climate change mitigation either by reducing the causes of $\mathrm{CO}_{2}$ emissions (e.g. higher energy efficiency, better insulation of buildings, increasing the use of renewable energy, etc) or by increasing the sinks (carbon sequestration), in which forests and wood products can play a major role.

Through the photosynthesis process, trees absorb $\mathrm{CO}_{2}$ from the atmosphere, while producing oxygen in return, and store carbon in their tissue and soil. After harvest this carbon remains stored in wood products until they are discarded or burnt. As a result, forests and wood products play an important role (both negative as positive) in the global carbon cycle through deforestation, forest conservation, afforestation and increasing application of wood in durable (construction) products.

Although afforestation in temperate regions is a positive development, on a global level carbon stocks in forest biomass still decreased by an estimated 7.5 Gigatons due to deforestation in (sub)tropical regions between 2000 and 2010 (see also figure 1), where a region of over 8 million hectares was deforested (FAO [1]).

Besides the conversion of forests to agricultural land or for development of infrastructure, one of the main causes of deforestation in tropical regions is (illegal) logging of tropical hardwood, which is high in demand worldwide because of its superior performance over softwood in terms of durability, hardness and often also dimensional stability.

Although the amount of certified sustainable sourced tropical hardwood on the market is increasing, also as a result of new legal requirements like the European Timber Regulation (EUTR) and the expanded Lacey Act in the USA, demand is

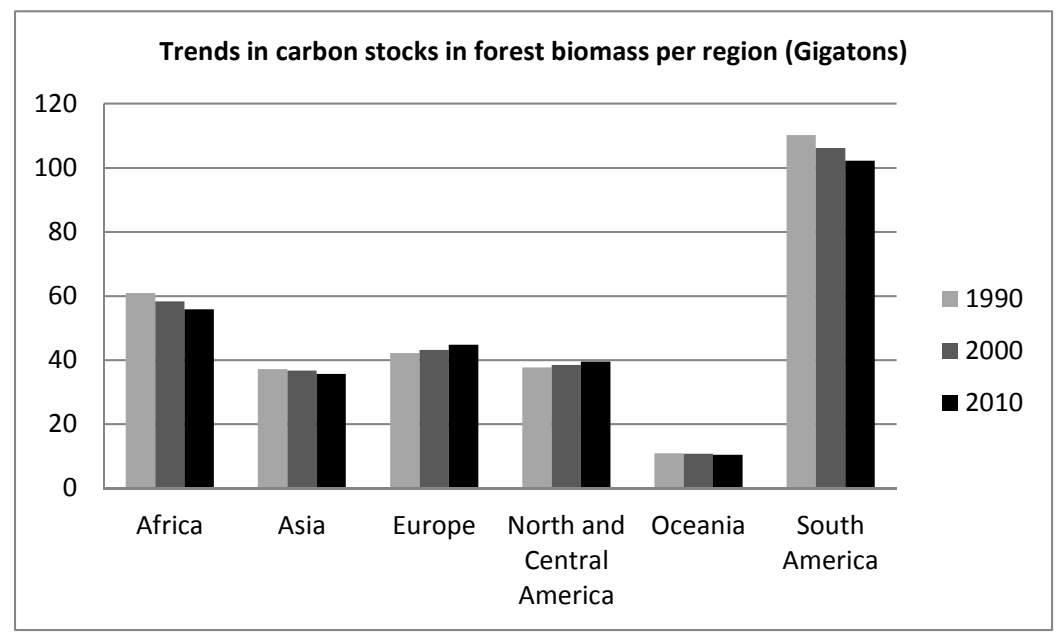

Figure 1: $\quad$ Trends in carbon storage in forests from 1990-2010 [1]. 
still considerably higher than supply and this trend is expected to continue with improving incomes in emerging economies. Therefore, other renewable solutions are required to reduce pressure on tropical rainforests. Plantation grown hardwoods, while providing an important resource, do not have the durability nor have the stability of increasingly scarce old growth forest harvests. Modified wood could play an important role in bridging this supply gap.

Wood modification is a means of improving the performance of abundantly available, but poor performance wood e.g. from boreal regions, without the typical negative impacts of traditional preservation techniques based on impregnation with toxic preservatives such as CCA or ACQ. Wood modification works at a molecular level to change the structure of the wood itself to improve many of its performance characteristics, most importantly the durability and dimensional stability.

There are a variety of wood modification techniques available, which can be divided into thermal modification (treatment under high temperature at low oxygen levels) and chemical modification (reacting the wood molecules with a chemical to permanently change the composition) of which acetylation is most likely the best known method. This process, which has been known and studied for over 80 years, involves the reaction of wood with acetic anhydride, through which the free -OH (hydroxyl) groups - causing the shrink and swell of wood and the susceptibility to decay - within the cell wall are replaced by more stable and hydrophobic acetyl groups. These non-toxic acetyl groups are naturally present in all woods but the acetylation process increases the acetyl content to a much higher level. As a result, the stability and durability of the wood significantly increases (e.g. durability to the highest class possible: Class 1 in EN 350). The coproduct of this process is acetic acid, otherwise known as vinegar in its dilute form, which is reused in a wide range of industries. These properties make acetylated wood a promising alternative in exterior applications where tropical hardwood is typically used such as external joinery, decking, cladding, and even structural applications (see figure 3).

Acetylated wood has been developed to commercial scale by the company Accsys Technologies under the brand name Accoya ${ }^{\circledR}$ wood. Accoya ${ }^{\circledR}$ 's performance has been widely reported as exceeding that of even the most durable

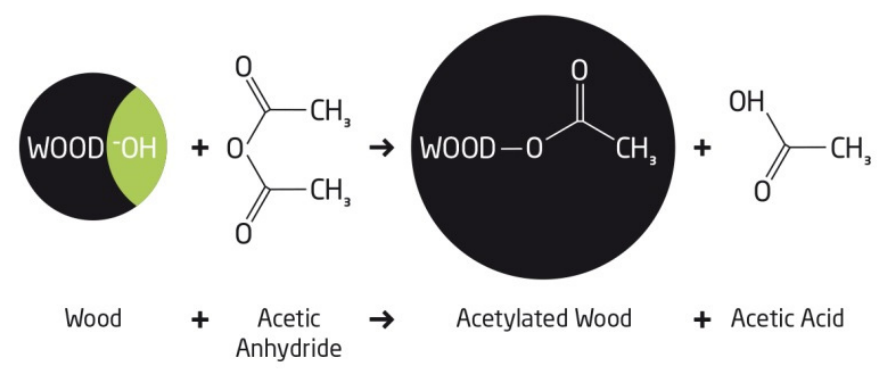

Figure 2: The acetylation process. 
and stable old growth tropical hardwoods (see for example Bongers et al. [2]). Accoya $^{\circledR}$ can be made from several wood species, but at the moment mainly radiata pine, alder and scots pine are used as input species. Although acetylation may sound like a solution to improve the carbon storage potential of temperate forests in through durable products, this benefit might have been compromised if the acetylation process relates to a disproportional release of greenhouse gas emissions during production and thus bears review.

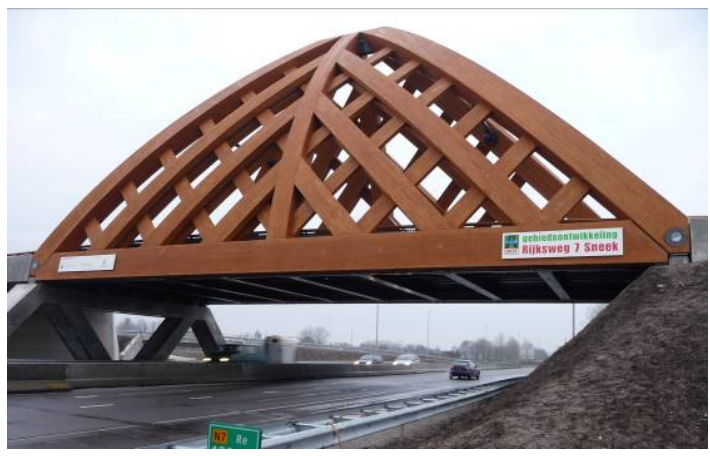

Figure 3: A large scale application of Accoya ${ }^{\circledR}$ wood - Sneek bridge, the Netherlands. The first ever heavy traffic road bridge with a wooden load bearing structure with an anticipated lifespan of 80 years.

\section{Methodology}

\subsection{Carbon footprint}

In a carbon footprint assessment, the greenhouse gas emissions (GHG) during the life cycle of a material are measured, and compared to alternative materials in terms of $\mathrm{kg} \mathrm{CO}_{2}$ equivalent $\left(\mathrm{CO}_{2} \mathrm{e}\right)$. Although not as comprehensive as the Life Cycle Assessment (LCA) methodology as defined in the ISO 14040/44 series [3], which besides the carbon footprint (Global Warming Potential) also includes environmental indicators such as acidification, euthrophication, smog, dust, toxicity, depletion, land-use and waste, a carbon footprint assessment is an excellent and commonly used tool to assess a material's environmental impact.

\subsection{Cradle-to-gate data (production phase)}

In 2013, a carbon footprint assessment was executed for Accoya ${ }^{\circledR}$ wood following the Greenhouse Gas Reporting Protocol guidelines WBCSD [4], based on a cradleto-gate scenario, thus until the factory gate of the acetylation plant of Accsys Technologies in Arnhem, the Netherlands. This encompasses the exact amount of raw materials, including their transport distance and production details (embodied energy), as well as the utilities consumed during the acetylation process (see figure 4). 


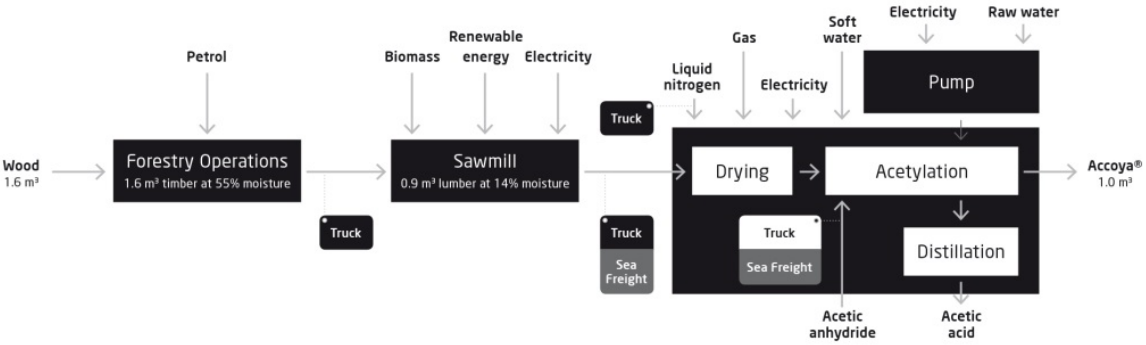

Figure 4: Diagram of inputs and outputs throughout the acetylation process based on a cradle-to-gate scenario.

The main input resources to produce acetylated wood are timber and acetic anhydride, with acetic acid as main co-product. This acetic acid is sold into a wide range of industries and therefore replaces merchant acetic acid on the market. As such the allocated GHG emissions of acetic acid are deducted from the emissions relating to the acetylation process, which is in line with PAS 2050 requirements (BSI [5]) as well as ISO 14044 [3], section 4.3.4.2 ("system expansion").

Figure 5 presents the cradle-to-gate carbon footprint results per cubic meter building material, which compares Accoya ${ }^{\circledR}$ made from scots pine to several commonly used material alternatives, based on the "market mix" figures, i.e. the mix of recycled and virgin materials on the market. Note that "sustainably sourced wood" in this paper relates to a relatively consistent biomass at the forestry level, in which the carbon stored in the standing volume remains stable, as a result of a sustainable management of the forest. In this paper "unsustainably sourced wood" relates to harvest based on Reduced Impact Logging (RIL) without replanting, with (significant) additional GHG emissions as a consequence.

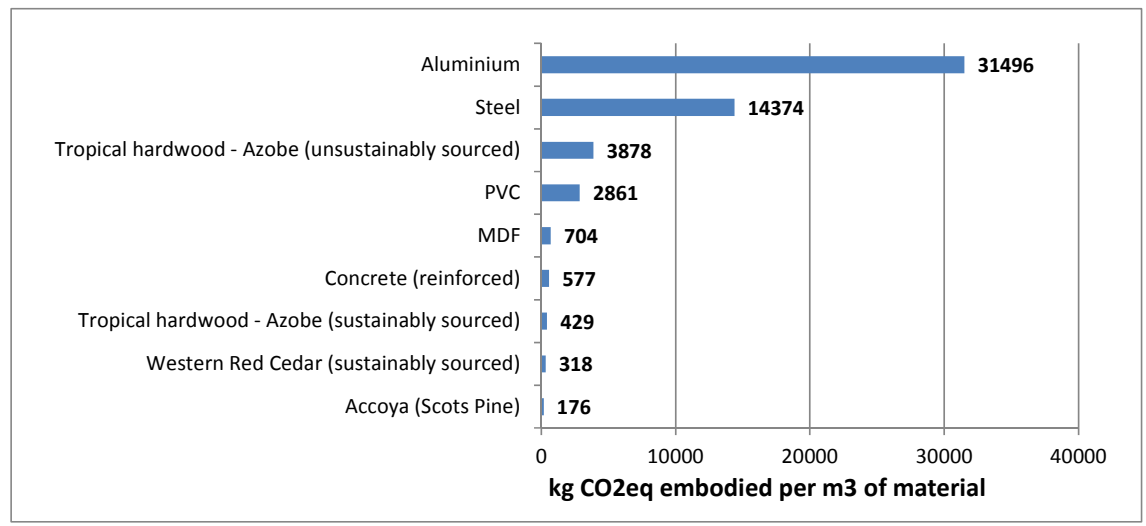

Figure 5: The GHG emissions of several building materials per cubic meter based on a cradle-to-gate scenario (Idemat [6], Ecoinvent [7]). 


\subsection{Cradle-to-grave data (including use phase)}

It is important to understand that the cradle-to-gate assessment, although providing an interesting insight in GHG emissions during production, does not provide a complete overview for a realistic comparison with other materials since additional use-phase and end-of-life related aspects of the various material alternatives are not yet included. These in-use emissions are likely to be centred around i) material properties such as density or strength, which dictate the volume of material required, ii) maintenance requirements including additional material use and frequency, iii) carbon sequestration in forests and end-products and iv) reuse, disposal and recycling routes available. Therefore, for a complete "cradle-tograve" assessment the carbon footprint results per cubic meter need to be "translated" to an application in which these in-use and end-of-life phase related aspects are included.

\subsubsection{Functional unit - material usage}

The functional unit chosen for the cradle-to-grave comparison is the bearing structure of a pedestrian bridge, with a size of $16 \times 3$ meters. The principal structural engineer of the Sneek bridge (see figure 3), Mr. Emil Lüning, designed the bearing structure of a reference pedestrian bridge, which, based on the constructional plan, for a fair comparison could be either executed in timber (acetylated scots pine and azobe), steel or concrete. The pedestrian bridge was assumed to be located in a non-marine situation in the centre of the Netherlands (province of Utrecht), and had to comply with all relevant Dutch building legislation for a pedestrian bridge. Additionally, the pedestrian bridge had to meet the same functional requirements (e.g. load bearing requirements) for all material alternatives. Figure 6 shows the schematic plan of the load bearing structure.
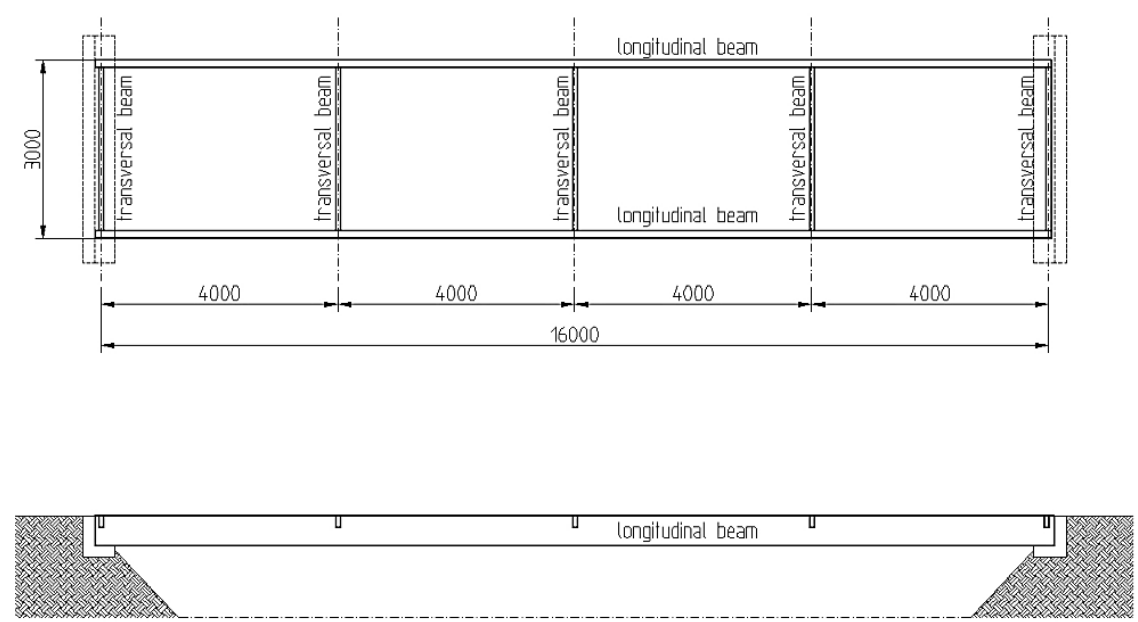

Figure 6: Constructional plan of the reference pedestrian bridge, above-view (top) and the side-view (bottom) (Lüning et al. [8]). 
In order to make a carbon footprint comparison for bridges designed with different materials, the net dimensions of the transversal and longitudinal beam in equal loading situations are provided in the table 1 below. For details about the structural calculations, is referred to [8]. For the carbon footprint calculations was calculated with $10 \%$ planing losses. Besides the main bearing structure, also the additional materials required for lengthening, laminating and initial coating (no maintenance coating assumed) are provided in the table.

Table 1: Material usage assumptions made for the carbon footprint assessment of a pedestrian bridge.

\begin{tabular}{|c|c|c|}
\hline & Material specification & $\begin{array}{l}\text { Amount of material } \\
\text { used (net figures) }\end{array}$ \\
\hline \multirow[t]{3}{*}{$\begin{array}{l}\text { Accoya }^{\circledR} \text { wood } \\
\text { (scots pine) }\end{array}$} & $\begin{array}{l}\text { Accoya }^{\circledR} \text { scots pine }\left(564 \mathrm{~kg} / \mathrm{m}^{3}\right) \\
2 \text { longitudinal beams } 16000 \times 160 \times 1134 \mathrm{~mm} \\
5 \text { transversal beams } 3000 \times 100 \times 405 \mathrm{~mm}\end{array}$ & $3615 \mathrm{~kg}$ \\
\hline & Polyurethane resin & $101 \mathrm{~kg}$ \\
\hline & Alkyd paint transparent, liquid, solvent based & $12.9 \mathrm{~kg}$ \\
\hline \multirow[t]{2}{*}{ Azobe } & $\begin{array}{l}\text { Azobe }\left(1000 \mathrm{~kg} / \mathrm{m}^{3}\right) \\
2 \text { longitudinal beams } 16000 \times 160 \times 1080 \mathrm{~mm} \\
5 \text { transversal beams } 3000 \times 100 \times 270 \mathrm{~mm}\end{array}$ & $5940 \mathrm{~kg}$ \\
\hline & Steel (market mix, for lengthening) & $297 \mathrm{~kg}$ \\
\hline Concrete & $\begin{array}{l}\text { Concrete (reinforced, } 40 \mathrm{~kg} \text { steel per } 1000 \mathrm{~kg} \text { ) } \\
2 \text { longitudinal beams } 16000 \times 300 \times 1100 \mathrm{~mm} \\
5 \text { transversal beams } 3000 \times 200 \times 290 \mathrm{~mm}\end{array}$ & $28575 \mathrm{~kg}$ \\
\hline Steel & $\begin{array}{l}2 \text { IPE } 600 \text { beams } \\
5 \text { HEA } 160 \text { beams } \\
\text { hot dip galvanized (zinc layer of } 50.7 \mu \mathrm{m})\end{array}$ & $4437 \mathrm{~kg}$ \\
\hline
\end{tabular}

For transport from the materials provider factory gate to building site $150 \mathrm{~km}$ was assumed, with for the wood alternatives an additional $50 \mathrm{~km}$ to a joinery factory for planing. For transport during the end-of-life phase $200 \mathrm{~km}$ was assumed in total (building site to sorting site to incineration plant).

The Life Cycle Inventory (LCI) data, required for the calculations are from the commonly referenced Ecoinvent v3 database [7] of the Swiss Centre for Life Cycle Inventories, and the Idemat 2014 database [6] of the Delft University of Technology. The Idemat LCIs are partly based on Ecoinvent LCIs.

\subsubsection{End-of-life credit}

In the Netherlands and other West European Countries, wood is separated from other waste and ends up in an electrical power plant. Although the efficiency of a modern coal fired electrical power plant is highest, i.e. 45\% IEA [9], current practice in Western Europe is that biomass is bought by energy providers and combusted in smaller electrical power plants specialized in biomass with an approx. $30 \%$ lower efficiency than the large coal plants. This energy output from biomass substitutes heat from fossil fuels, leading to a "carbon credit" for the avoided use of fossil fuels. Based on the Idemat 2014 database [6] the end-of-life credit for electricity production from wood waste is then $0.819 \mathrm{~kg} \mathrm{CO}_{2}$ eq for 
softwood $\left(\right.$ Accoya $^{\circledR}$ ) and $0.784 \mathrm{~kg} \mathrm{CO}$ eq for hardwood (azobe). The above procedure is according to ISO 14040 and 14044 [3], and according to the European LCA manual EC-JRC [10]. For the wood alternatives the effects of the carbon sequestration on a global level can be taken into account as "optional" before the final result can be calculated. Note that for the steel alternatives the recycling credits during end-of-life are already included in the embodied emissions of the material, based on the European market mix figures (i.e. $44 \%$ recycled for steel).

\subsubsection{Carbon sequestration credit}

Through the photosynthesis process biogenic $\mathrm{CO}_{2}$ is first taken out of the air at the forest, the carbon is then stored in forest and wood products, after which it is released back to the atmosphere at the end-of-life. So biogenic $\mathrm{CO}_{2}$ is recycled, and its net effect on global warming is zero, unless it is burnt for energy during end-of-life, substituting fossil fuels, as explained above.

Thus the positive effect of carbon storage cannot be analysed on the level of one single product, although two important LCA systems, the ILCD Handbook [10] and the PAS 2050:2011 Specification [5], do provide an optional credit for temporary carbon storage based on discounting of the delayed $\mathrm{CO}_{2}$ emissions. However, this "optional" method leads to an overestimation of the benefits of temporary fixation of biogenic $\mathrm{CO}_{2}$.

The effects of carbon sequestration can be better understood when we look at a global system level. On a global scale, $\mathrm{CO}_{2}$ is stored in forests (and other vegetation), in the ocean, and in products (buildings, furniture, etc). One should realise that, when there is no change in the standing volume of forests and no change in the total volume of wood in building and products (furniture, etc.), there is no change in sequestered carbon and therefore no effect on carbon emissions.

A better approach to incorporate carbon sequestration in LCA is proposed by Vogtländer et al. [11]. This paper gives a scientific analysis of the issue, bringing the calculations in LCA in line with the Tier-2 calculations of the IPPC. In the following text of this section, this new approach is summarised, and is applied to the case of the pedestrian bridge for the wood scenarios.

Figure 7 is a simplified schematic overview of the highest aggregation level of the global carbon cycle, and shows that the anthropogenic $\mathrm{CO}_{2}$ emissions on a global scale can be characterised by three main flows:

i) carbon emissions per year caused by burning of fossil fuels: $6.4 \mathrm{Gt} /$ year (Solomon et al. [12]);

ii) carbon emissions per year caused by deforestation in tropical and sub-tropical areas: $1.93 \mathrm{Gt} /$ year [1]. Note that this also applies to azobe as the forest area in Central Africa is decreasing;

iii) carbon sequestration per year by re-growth of forests on the Northern Hemisphere (Europe, North America, China): $0.85 \mathrm{Gt} /$ year [1]. Note that this also applies to Scandinavian scots pine.

The consequence of the above is that there is only additional carbon storage on a global scale, when there is market growth of sustainable wood production from temperate and especially boreal regions in the Northern Hemisphere, including scots pine from Scandinavia. This market growth leads to more plantations and 


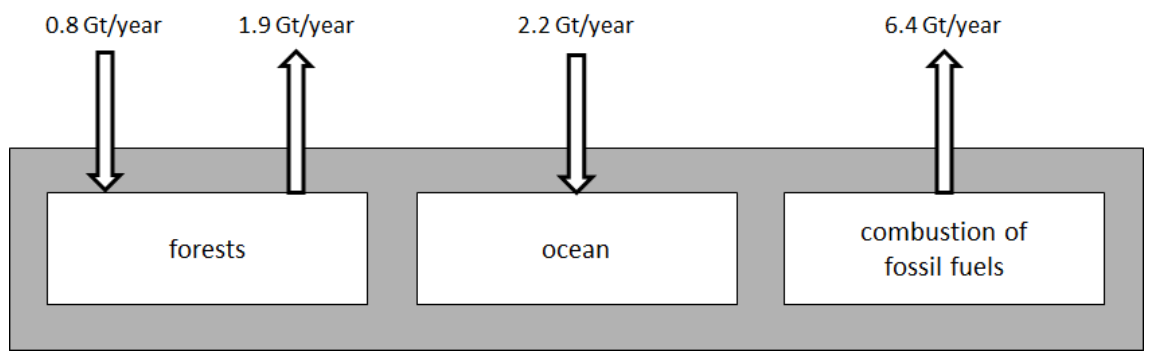

Figure 7: Global anthropogenic fluxes of $\mathrm{CO}_{2}(\mathrm{Gt} / \mathrm{year})$ over the period 20002010 [11].

production forests and a higher volume of wood applied in the building industry. In contrast, additional demand of tropical hardwood, such as azobe, leads to a decrease in forest area since the demand is higher than the supply of plantations, so it leads to less sequestered carbon.

For the carbon sequestration credit calculation following global land-use change and increasing application in the building industry, the following 5 steps should be taken in case of the situation of Scandinavian scots pine (used to produce Accoya $\left.^{\circledR}\right)$. For detailed calculations see [11].

1. The calculation of the relationship (ratio) of carbon stored in forests and carbon stored in end-products: $1 \mathrm{~kg}$ of wood product relates to $6.97 \mathrm{~kg} \mathrm{CO}_{2}$ storage in the forest.

2. The calculation of a land-use change correction factor (to cope with the fact that there was another type of biomass before the area was changed to forests/plantations); For European boreal softwood, we assume that there was grass before the afforestation since the boreal areas are hardly used for agriculture. This provides a land-use change correction factor of 0.953 .

3. The calculation of the extra stored carbon in forests and plantations, because of growth of boreal softwood production, and its allocation to the end-products, based on a yearly growth of European timber production of $2.3 \%$ UNECE [13]. Step 1, step 2 and step 3 result in $6.97 \times 0.953 \times 0.023=0.15 \mathrm{~kg} \mathrm{CO}_{2}$ per kilogram dry planed boreal softwood.

4. The calculation of the extra stored carbon in the building industry, because of growth of the volume; assuming application losses of $10 \%$ this relates in total to an additional credit of $0.9 \times 0.5 \times 3.67 \times 0.023=0.04 \mathrm{~kg} \mathrm{CO}_{2}$ per kilogram planed timber.

5. The final calculation of the total result of carbon sequestration: the sum of the result of step 3 plus the result of step 4 .

In the case of Scandinavian scots pine, as a result of sustainable management practices and forest area growth because of increasing demand, this leads to a total carbon sequestration credit of $0.19 \mathrm{~kg} \mathrm{CO}_{2}$ per kilogram dry planed timber.

Tropical hardwood, such as azobe, does not have a carbon sequestration credit. In the best scenario the carbon sequestration credit is zero, which is the case for sustainably managed plantation wood. However, for most tropical hardwood, the 
situation is worse: the deforestation of natural rain forests leads to a debit of carbon sequestration (see figure 7). As it is very difficult to capture the actual deforestation situation in tropical regions it is not yet possible to allocate this debit to tropical hardwood used in the building industry. To still provide an indication of this debit, the cradle-to-gate figures for unsustainably sourced azobe have been calculated on the bases that trees have been removed from the forest with Reduced Impact Logging, without planting new trees back. In this calculation the following ratios are applied: "sawn timber"/"standing volume above ground" $=0.62$ (Vogtländer et al. [14]), the root/shoot ratio $=0.37$ (CDIAC [15]), and the carbon fraction $=0.47$ (the result of this calculation is given in figure 5).

Note that land-use change is incorporated in LCA indicators like Recipe and Eco-costs, and is modelled via the biodiversity of land. Degradation of biodiversity is strongly related to the harvesting of tropical hardwood. For example, globally, FSC certified tropical hardwood is partly sourced from plantations and semi-natural forests, but the lions share (64\%) is still coming from natural forests (harvested with Reduced Impact Logging), having a negative impact on biodiversity.

\section{Results}

The results of the cradle-to-grave carbon footprint comparison for the bearing structure of a pedestrian bridge are presented in the graph below.

\begin{tabular}{|c|c|c|c|c|c|c|c|c|}
\hline \multirow{7}{*}{ 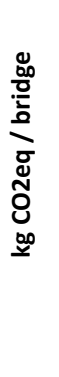 } & \multicolumn{8}{|l|}{30000} \\
\hline & \multicolumn{8}{|l|}{25000} \\
\hline & \multicolumn{4}{|l|}{20000} & & & & \\
\hline & \multicolumn{8}{|l|}{10000} \\
\hline & \multicolumn{8}{|l|}{5000} \\
\hline & \multicolumn{8}{|l|}{-5000} \\
\hline & -10000 & $\begin{array}{l}\text { Input } \\
\text { materials }\end{array}$ & Transport & Processing & Coating & $\begin{array}{c}\text { Carbon } \\
\text { sequestrati } \\
\text { on }\end{array}$ & End of Life & TOTAL \\
\hline \multicolumn{2}{|c|}{ Accoya Scots Pine } & 1767 & 111 & 111 & 35 & -567 & -3290 & -1832 \\
\hline \multicolumn{2}{|c|}{ Azobe (sustainable) } & 3377 & 186 & 103 & 32 & & -5174 & -1476 \\
\hline \multicolumn{2}{|c|}{ - Azobe (unsustainable) } & 26144 & 186 & 103 & 32 & & -5174 & 21290 \\
\hline \multicolumn{2}{|c|}{ Concrete } & 6594 & 700 & & & & & 7295 \\
\hline \multicolumn{2}{|c|}{$\square$ Steel } & 7909 & 109 & & 279 & & & 8297 \\
\hline
\end{tabular}

Figure 8: Greenhouse gas emissions $\left(\mathrm{kg} \mathrm{CO}_{2} \mathrm{eq}\right)$ per process step for the bearing structure of a pedestrian bridge.

The graph reveals that because of the limited emissions during production and credits that can be earned by incineration for energy production in the end-of-life phase, sustainably sourced azobe and Accoya ${ }^{\circledR}$ made from scots pine are $\mathrm{CO}_{2}$ negative over the full life cycle. Non-renewable materials (steel and concrete) perform considerably worse than sustainably sourced wood, especially because of 
the high embodied energy (emissions during production) but for concrete also for transport emissions because of the high weight.

However, in the case of unsustainably sourced azobe, the picture totally shifts: from one of the best performing alternatives, azobe becomes the worst performing alternative when the negative effect on carbon sequestration of tropical rainforests is taken into account. This shows the importance of conservation of tropical rainforests as they act as important, yet very vulnerable, carbon sinks in the global carbon cycle.

Simultaneously it highlights the potential important role of non-toxic wood modification technologies such as acetylation; These technologies enable abundantly available softwood from temperate regions to substitute tropical hardwood, and even carbon intensive materials such as metals and concrete, further reducing greenhouse gas emissions. Furthermore, they provide a powerful drive for increased afforestation as softwood species can now serve as input for high performance wood, which could further increase the market adoption of boreal wood and thus subsequent reforesting, which results in more global carbon sequestration.

\section{References}

[1] FAO, Global Forest Resources Assessment. Food and Agriculture Organization of the United Nations, Rome, 2010.

[2] Bongers, F., Hague, J., Alexander, J., Roberts, M., Imamura, Y., Suttie, E., The resistance of high performance acetylated wood to attack by wooddestroying fungi and termites, Proc. IRG Annual Meeting (ISSN 20008953) Stockholm, Sweden, pp. 3-17, 2013.

[3] ISO, Environmental management - Life cycle assessment - Requirements and guidelines 14044:2006, ISO, 2006.

[4] World Business Council for Sustainable Development (WBCSD), World Resources Institute (WRI). The Greenhouse Gas Protocol: A Corporate Accounting and Reporting Standard (Revised Edition), WBCSD, WRI, Geneva, Switzerland, 2004.

[5] BSI, PAS 2050: 2011 - Specification for the assessment of the life cycle greenhouse gas emissions of goods and services. British Standards Institution (BSI), London, United Kingdom, 2011.

[6] Idemat 2014 database. Available through www.ecocostsvalue.com, tab data Delft University of Technology, the Netherlands, 2014.

[7] Ecoinvent V3 database. Available through www.ecoinvent.ch, 2013.

[8] Lüning, H.E., Tran, V.T., Data for LCA of timber, concrete and steel bridge. Lüning Consulting Civil and Structural Engineers, Doetichem, the Netherlands, 2009.

[9] IEA. Biomass for Power Generation and CHP, Website, https://www.iea.org/techno/essentials3.pdf, 2007.

[10] European Commission, Joint Research Center. General guidance document for Life Cycle Assessment (LCA), International Reference Life Cycle Data System (ILCD) Handbook, European Commission, 2012. 
[11] Vogtlander, J.G., van der Velden, N.M., van der Lugt, P., Carbon sequestration in LCA, a proposal for a new approach based on the global carbon cycle; cases on wood and on bamboo. International journal of LCA (19) pp. 13-23, 2014.

[12] Solomon, S., Qin, D., Manning, M., Chen, Z., Marquis, M., Averyt, K.B., Tignor, M., Miller, H.L., IPCC Fourth Assessment Report: Climate Change (AR4), The Physical Science Basis, Contribution of Working Group I to the Fourth Assessment Report of the Intergovernmental Panel on Climate Change, Cambridge University Press, Cambridge, 2007.

[13] United Nation Economic Commission for Europe, European Forest Sector Outlook Study 1960-2000-2020, Geneva Timber and Forest Study Paper 20. UNECE, 2005.

[14] Vogtlander, J.G., van der Lugt, P., Brezet, J., The sustainability of bamboo products for local and Western European applications, LCAs and land-use. Journal of Cleaner Production, pp 1260-1269, 2010.

[15] CDIAC, New IPCC Tier-1 Global Biomass Carbon Map for the Year 2000, ttp://cdiac.ornl.gov/epubs/ndp/global_carbon/carbon_documentation.html\# tables, 2014. 